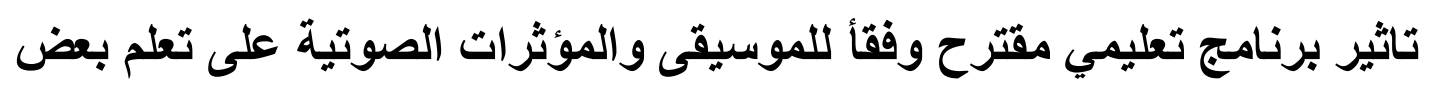

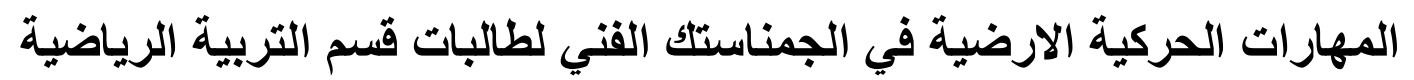

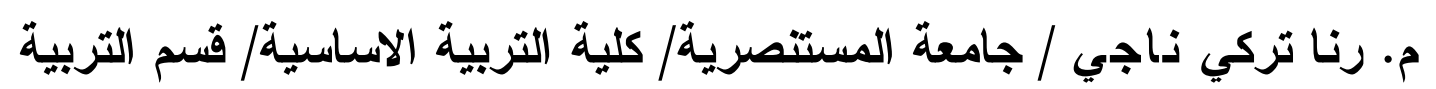
الرياضية

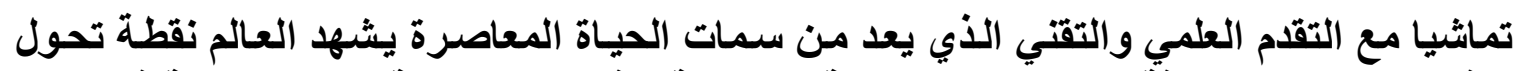
جديدة في ميادين الحياة كافة ومنها ميدان التربية الرياضية الذيّة الذي احتل مكانـة بـارزة ومهمـة في حياة

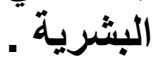

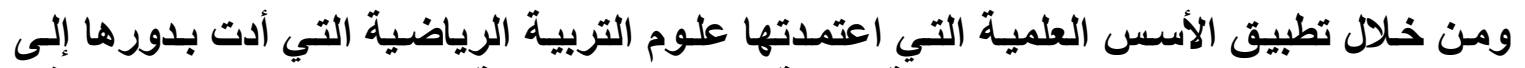

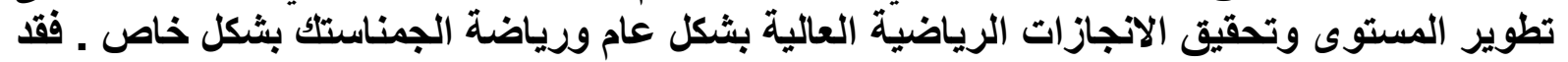

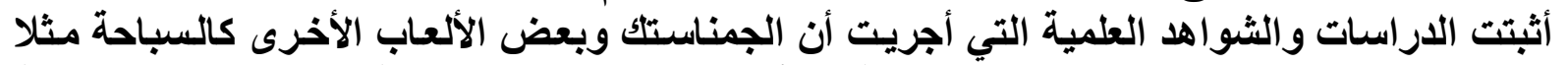

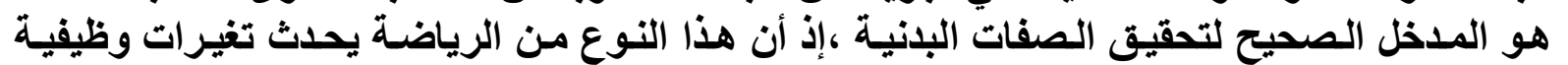

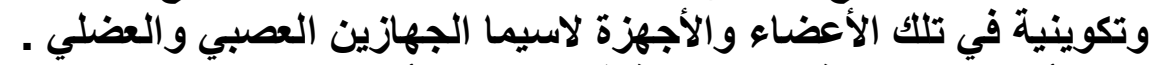

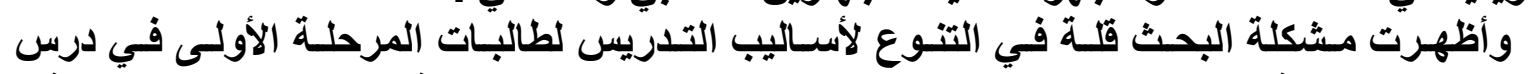

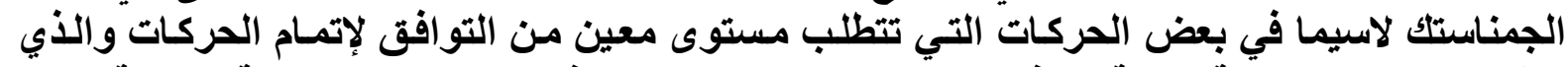

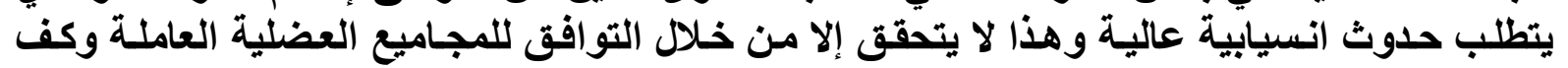

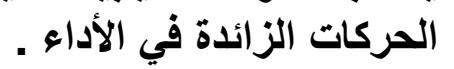

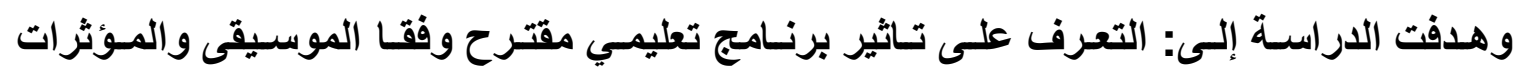

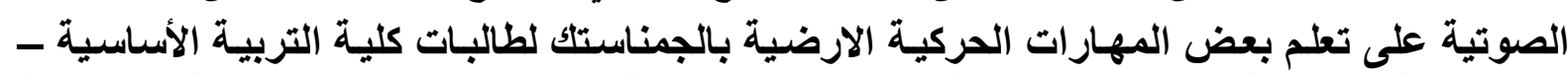

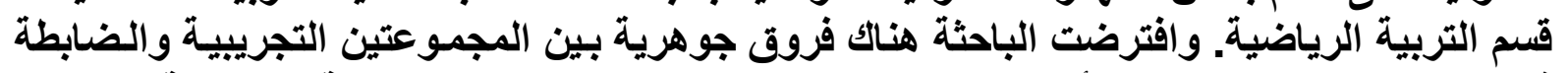

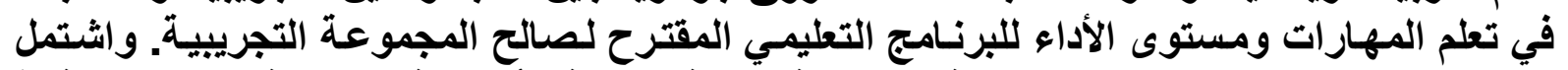

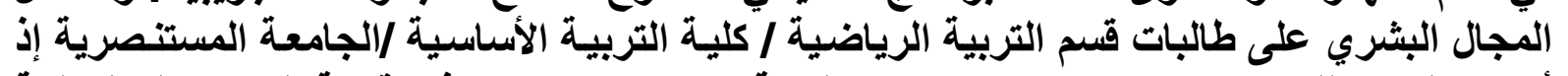

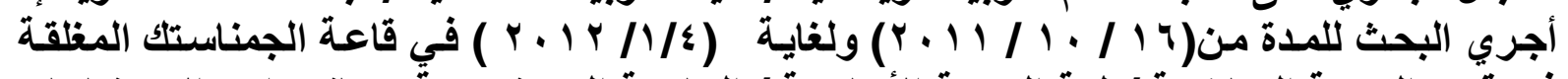

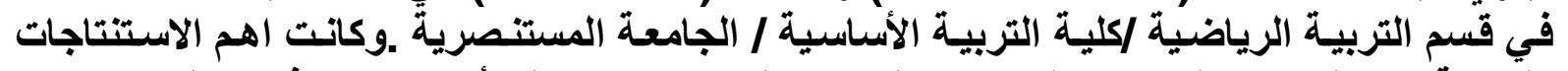

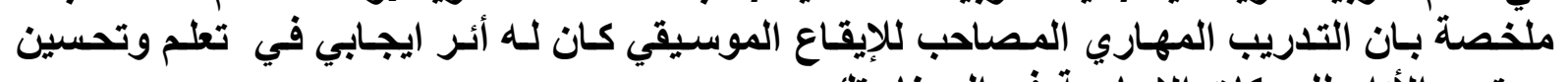

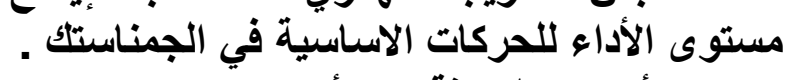

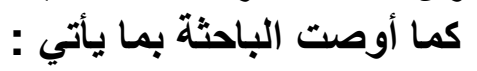
ضرورة استخدام الإيقاع الموسيقي عائي عند تعليم مهارات الجمناستك (الحركات الأرضية).

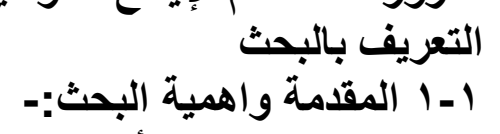

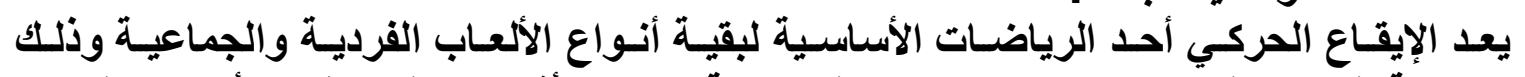

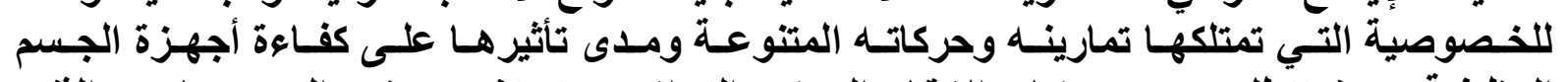

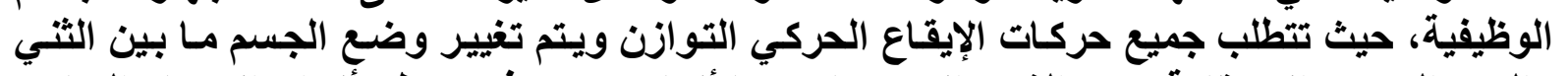

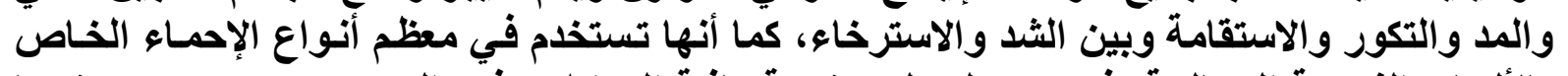

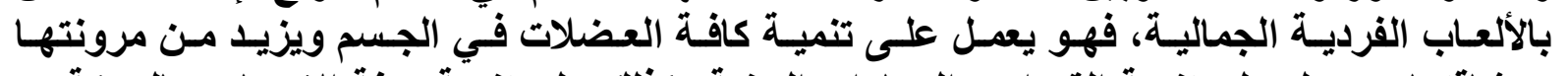

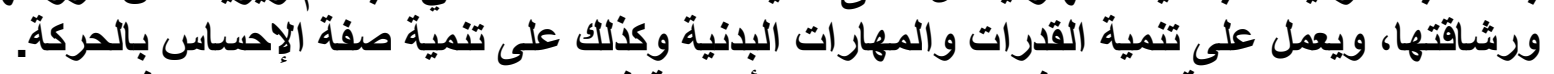

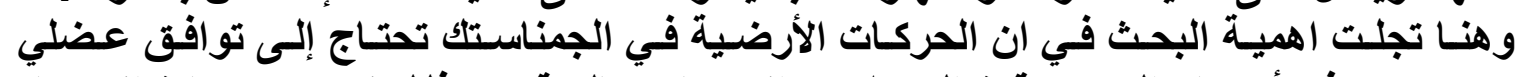

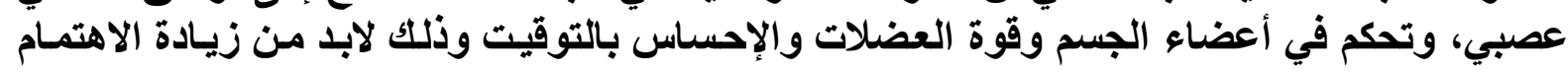


بالإيقاع الموسيقي للحصول على حركات انسيابية رشيقة وجميلة لأن مجرد الإحساس بالإيقاع يعطي

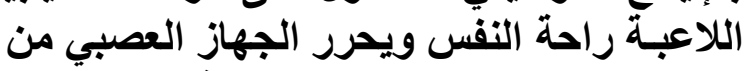

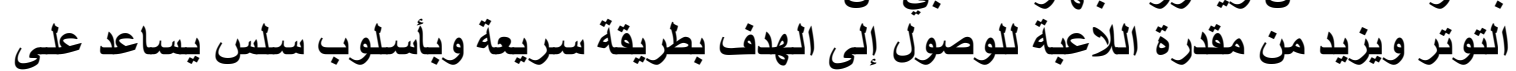
تأخير ظهور التعب .

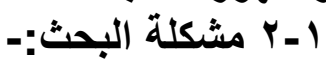

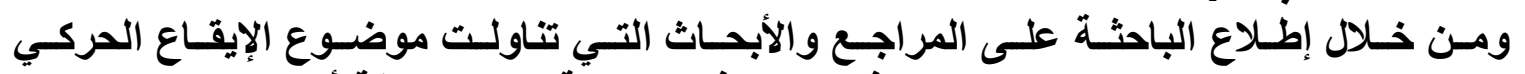

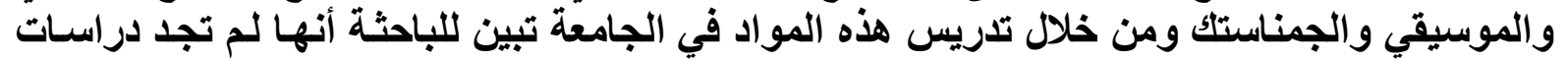

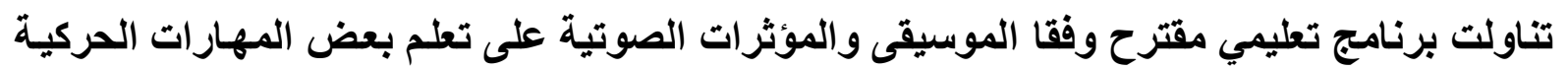

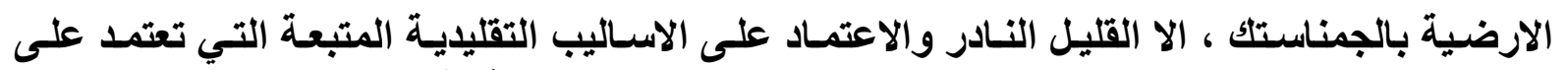

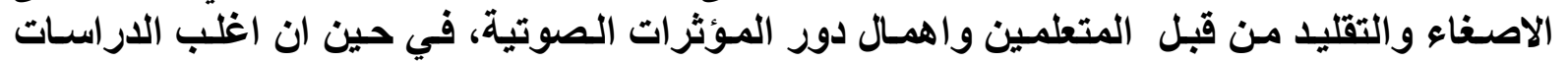

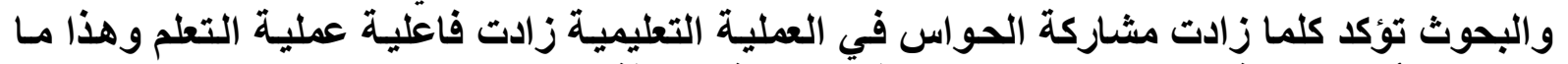

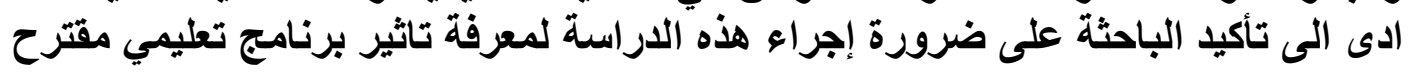

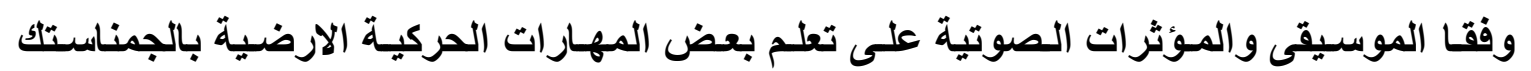
لطالبات قسم التربية الرياضية.

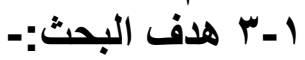

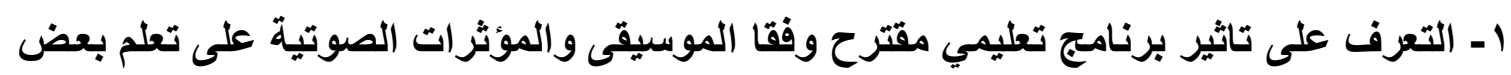

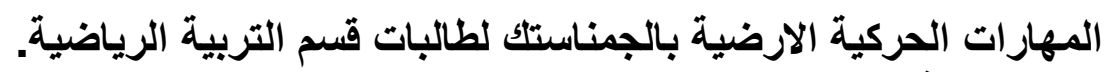

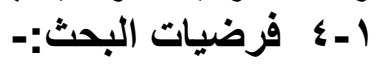

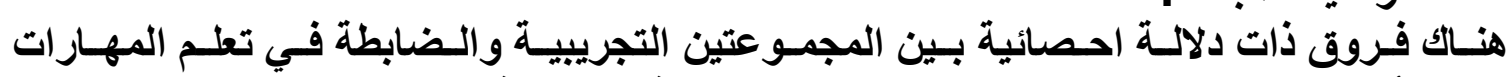

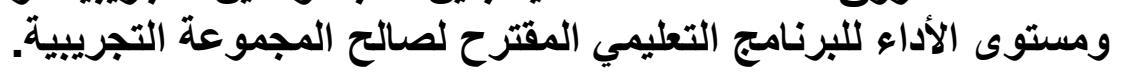

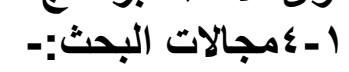

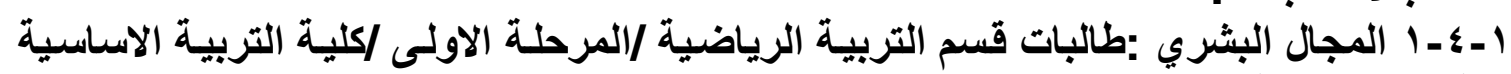

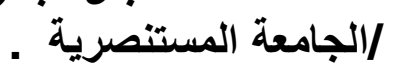

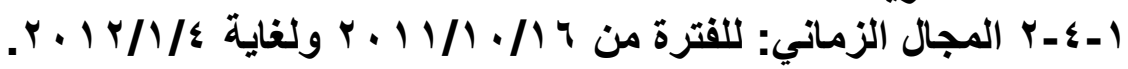

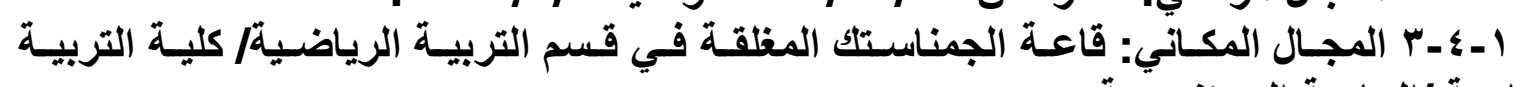
الاساسية /الجامعة المستنصرية المبانية

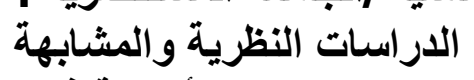
r - 1 الحركات الأرضية في الجمابهة الجمناستك الفني:-

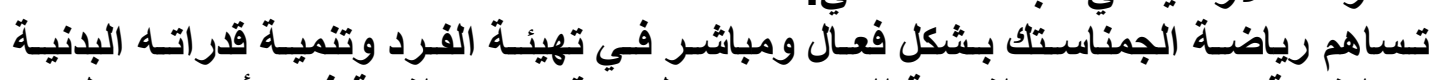

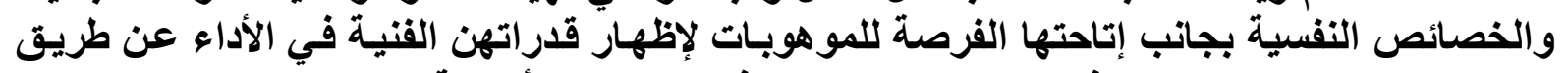

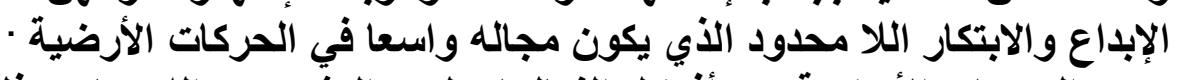

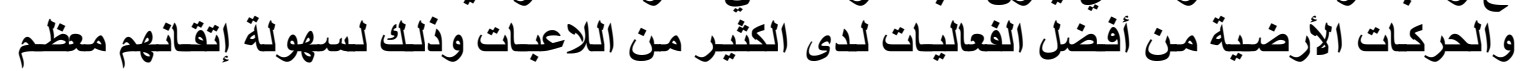

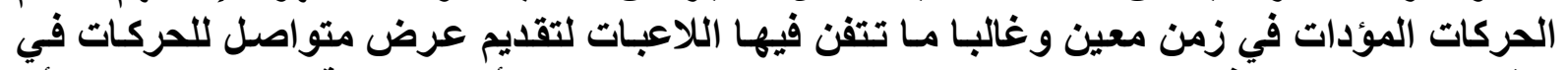

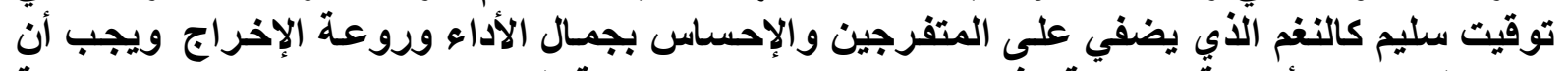

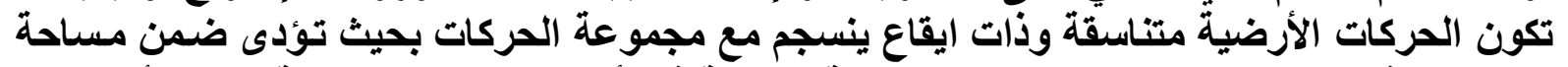

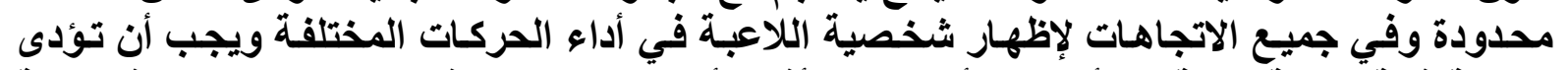

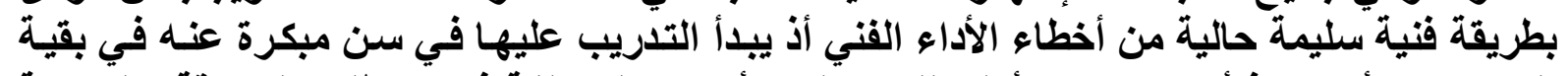

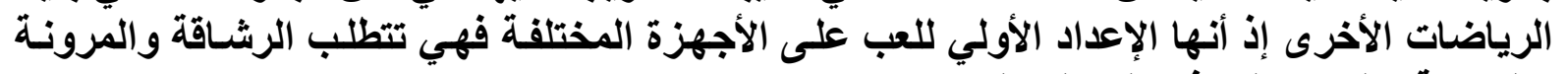

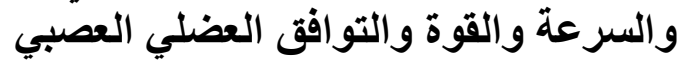




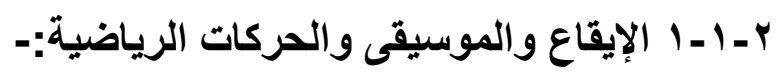

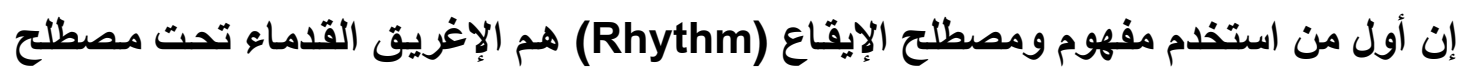

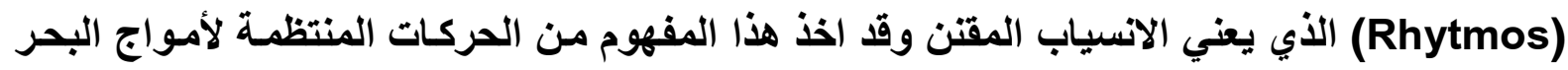

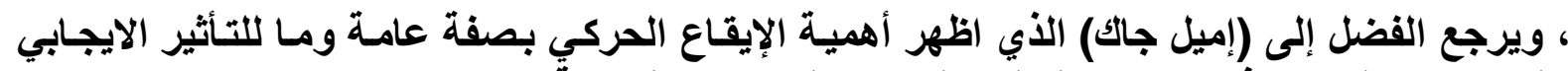

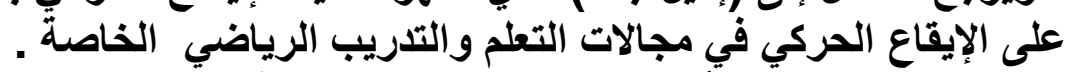

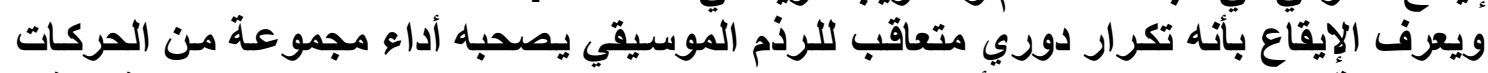

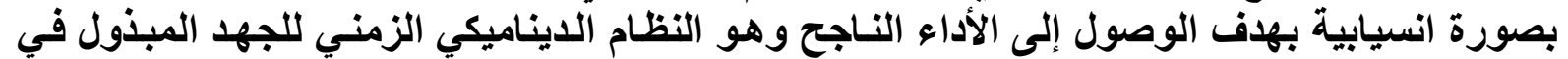

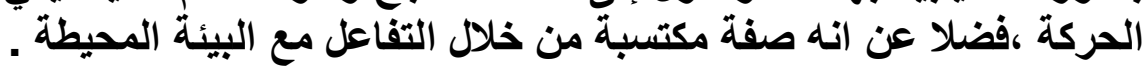

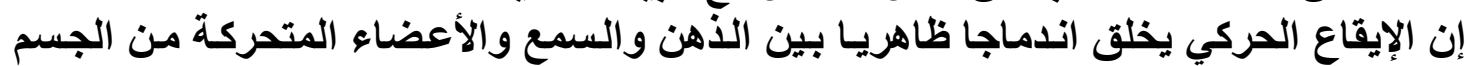

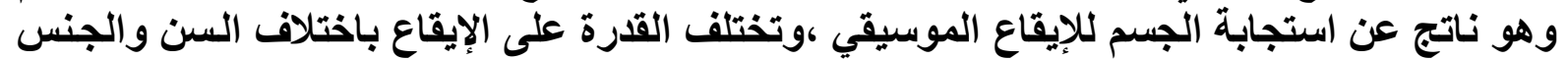

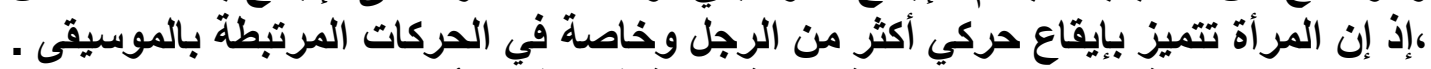

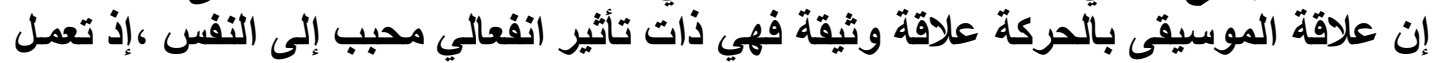

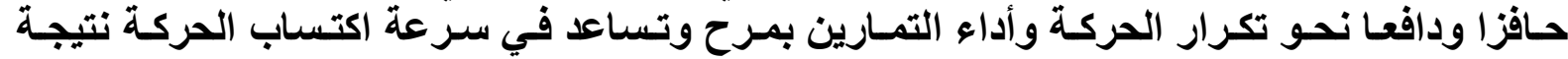

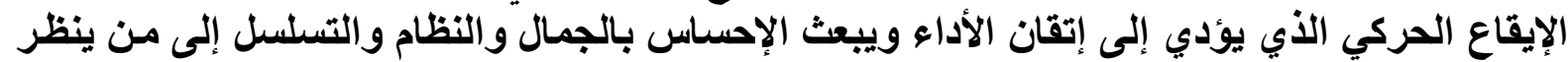

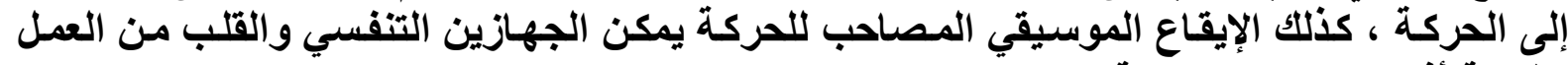

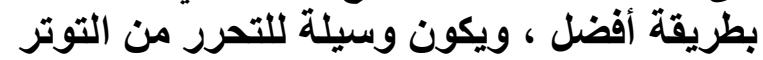

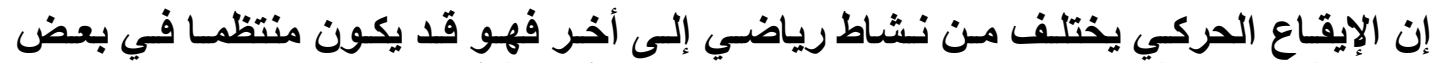

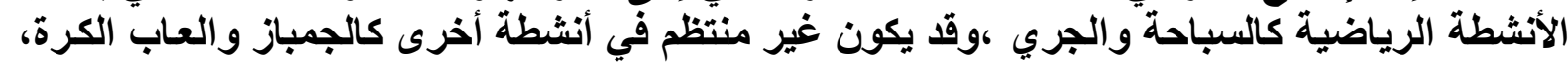

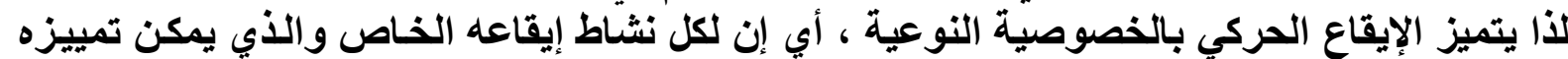

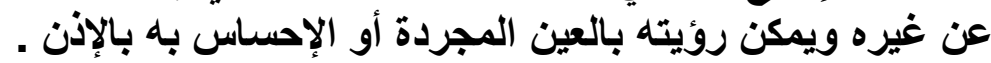

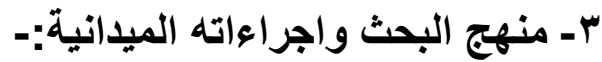

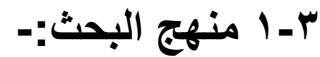

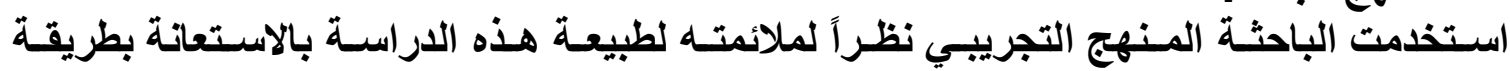
المجموعات المتكافئة .

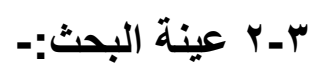

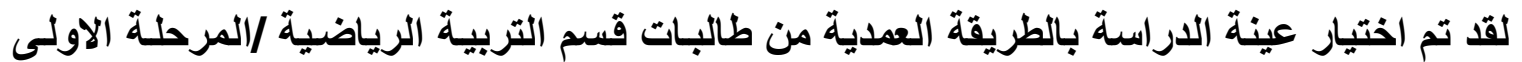

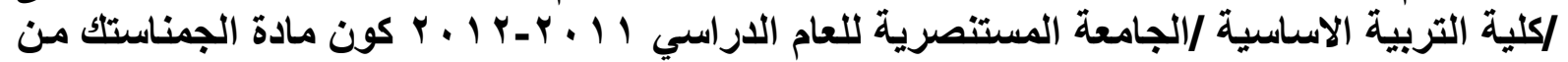

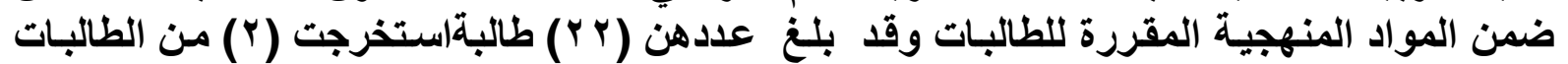

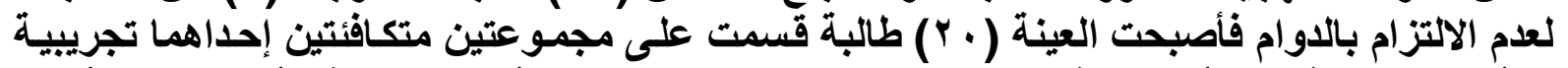

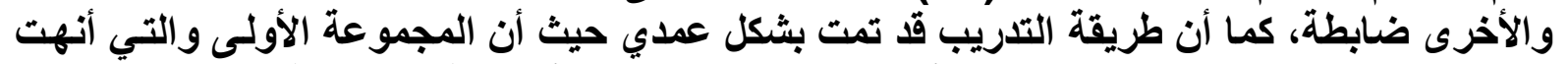

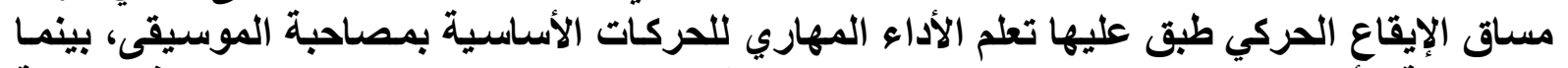

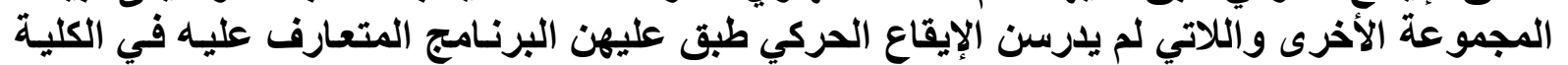

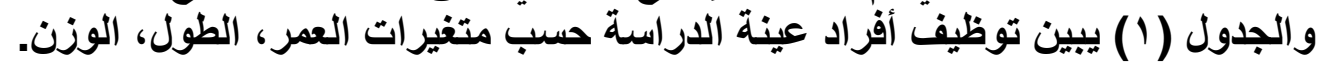

جدول (1)

عينة الاراسة حسب متغيرات العمر ،الطول ،الوزن، (ن = · r ) 


\begin{tabular}{|c|c|c|c|c|}
\hline \multicolumn{2}{|c|}{ المجموعة الضابطة ( • (1) } & \multicolumn{2}{|c|}{ المجموعة التجريبية ( 1) } & \multirow[t]{2}{*}{ المتغيرات } \\
\hline$\varepsilon$ & س - - ن & $\varepsilon$ & س & \\
\hline$\cdot, \vee \wedge$ & $1 \wedge, \wedge$. & $1,1 \%$ & $1 \wedge, \wedge$. & العمر (سنة) \\
\hline$\varepsilon, \leqslant Y$ & $1,7$. & $\varepsilon, 9 V$ & 1,09 & الطول (سم) \\
\hline$\varepsilon, \mu$ & ० , 7. & $V, Y_{1}$ & $\Delta \vee, \ldots$ & الوزن (كغم) \\
\hline
\end{tabular}

وقد تم إجراء التكافؤ بين المجموعتين والجدول (ץ) يبين ذلك.

جدول (r)

تكافؤ مجموعتي البحث في متتفيرات الدراسة

\begin{tabular}{|c|c|c|c|c|c|c|c|c|}
\hline \multirow{2}{*}{ اللالالة } & \multirow{2}{*}{ ى اللالالة } & \multirow{2}{*}{ t الجدولية } & \multirow{2}{*}{ المسوبة } & \multicolumn{2}{|c|}{ 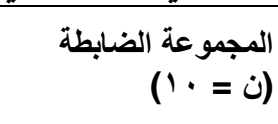 } & \multicolumn{2}{|c|}{ التجريبية = . 1 (1) } & \multirow{2}{*}{ ليرات } \\
\hline & & & & $\varepsilon \pm$ & س- & $\varepsilon \pm$ & ـ ـ ـ ـ & \\
\hline مغنوي & $1,$. & & صفر & $\cdot, \mathrm{\vee A}$ & $1 \wedge, \wedge$ & $1,1 \pi$ & $\wedge$. & لـعـة \\
\hline معنوي & V V V V & 1.7 & " \&, & 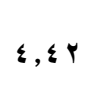 & 1,7 & $\&, 9 \mathrm{~V}$ & 1,09 & لطول \\
\hline معنوي & •, Ar & & TY, & $\varepsilon, \Gamma_{0}$ & $0 v, r$ & $v, r)$ & ${ }^{0} \mathrm{v},$. & (كونخ \\
\hline
\end{tabular}

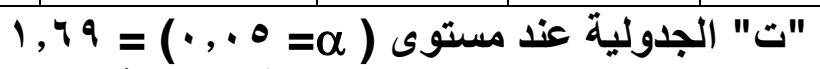

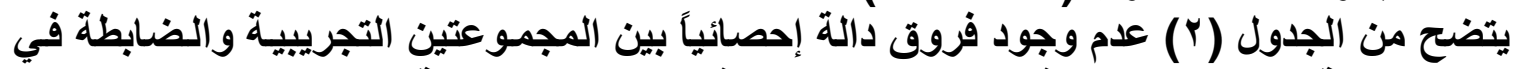

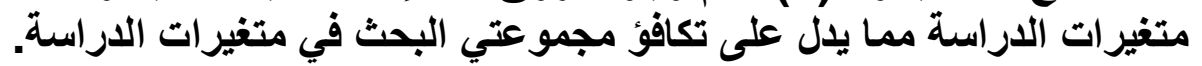

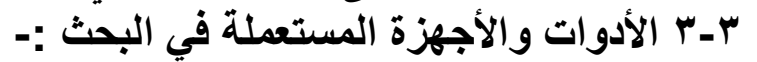

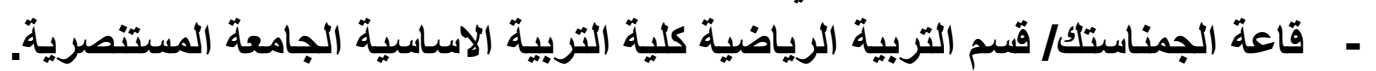

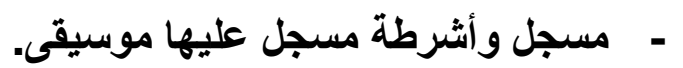

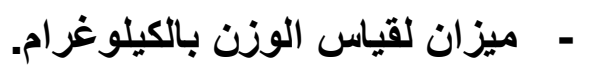

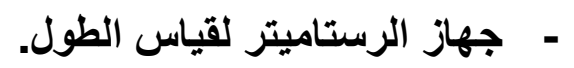

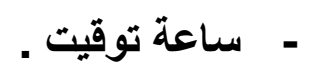

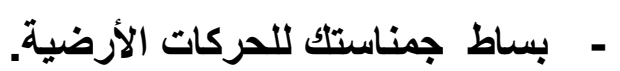

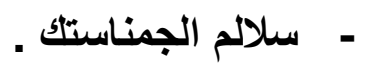
r- ــ البرنامج المستعمل في عملية التعليم للمهارات الحركية الارضية في الجمناستك:-

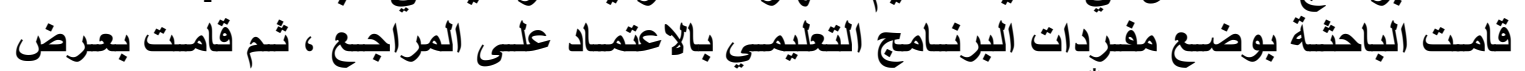

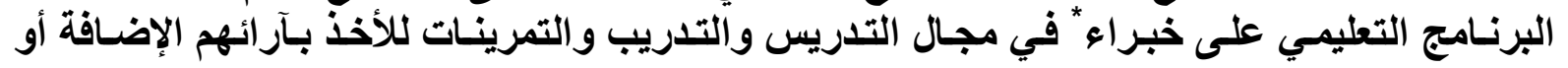


التعديل او الإلغاء، وبناء على آراء الخبراء تم التعديل في البرنـامج حتى أصبح في صورته النهائية

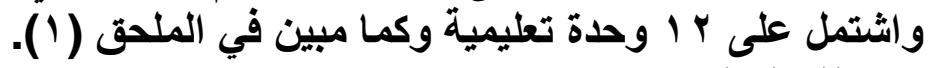

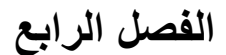
ك - ك عرض النتائج ومناقشتُها:-

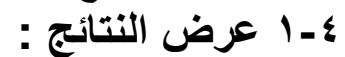
من أجل دراسـة الفروق بين أفراد المجموعتين التجريبية والضابطة، تم استخدام اختبار "ت التهاب

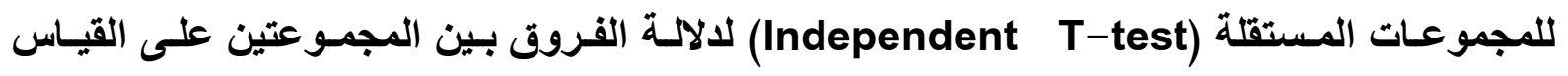
البعدي على المهارات قيد الدراسة، والجدول (r) يبين ذلك.

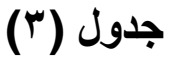

يبين الاوسـاط الحسابية والانحرافـات المعياريـة وقيمـة (T) الجدوليـة والمحسوية ونـوع الدالالـة

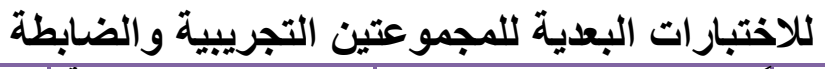

\begin{tabular}{|c|c|c|c|c|c|c|c|c|}
\hline \multirow[t]{2}{*}{ الدلالة مستوى } & \multirow[t]{2}{*}{ الجدولية } & \multirow{2}{*}{ 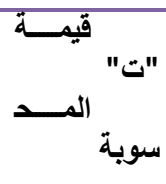 } & \multicolumn{2}{|c|}{ 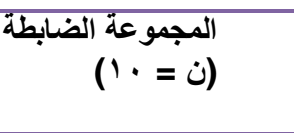 } & \multicolumn{2}{|c|}{ 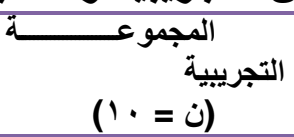 } & \multirow[t]{2}{*}{ الحركــــــــــات } & \multirow[t]{2}{*}{ لرقم } \\
\hline & & & $\varepsilon \pm$ & س & $\varepsilon \pm$ & س & & \\
\hline مغنوي & I. $v .1$ & $V, r q$ & דוr, & $v^{v}, v^{\prime}$ & $\cdot, r$ & $\lambda_{, \lambda r}$ & الميزان الأمامي. & 1 \\
\hline مغنوي & & $11, \wedge$ & •, YY & $\begin{array}{ll}, 0 \wedge \\
\end{array}$ & $\cdot, 1$ & צ ז, & الاحرجة الأمامية. & r \\
\hline مغنوي & & $V, \cdot r$ & צT, & r & $\cdot, Y$ & $\wedge^{\wedge}$ & الوقوف على اليدين. & $r$ \\
\hline
\end{tabular}

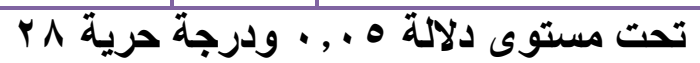

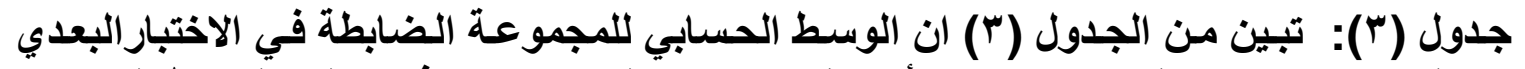

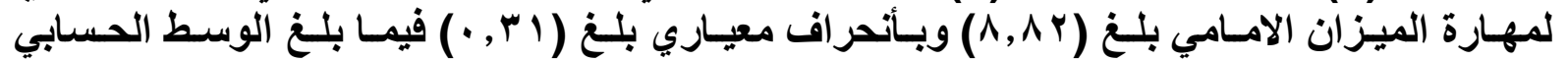

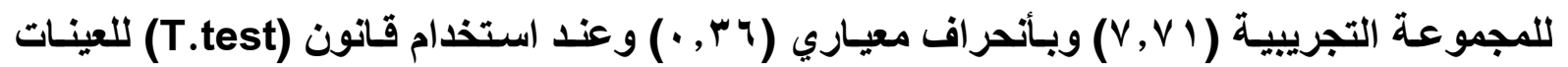

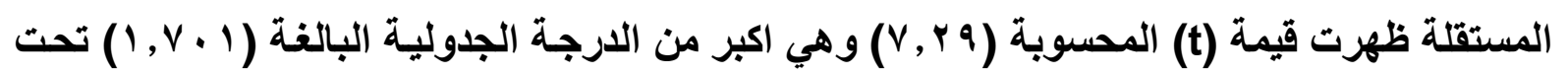

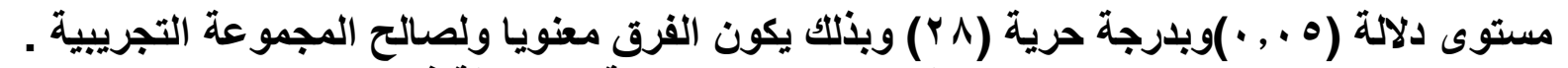

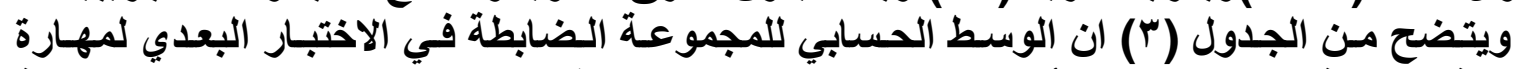

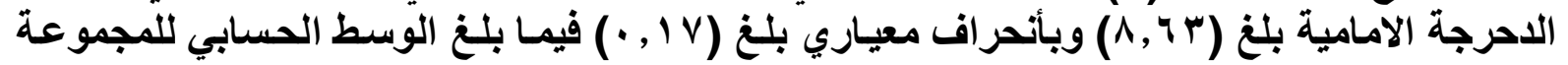

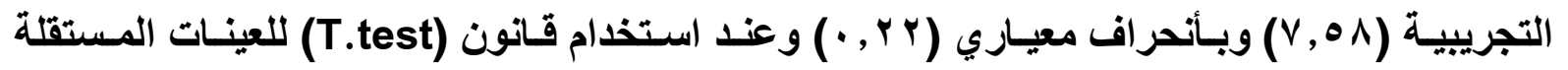

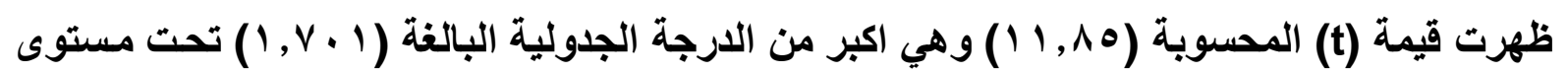

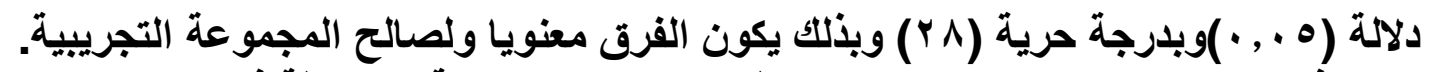

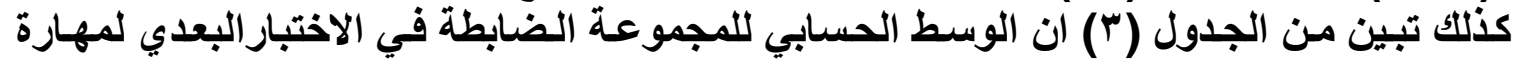

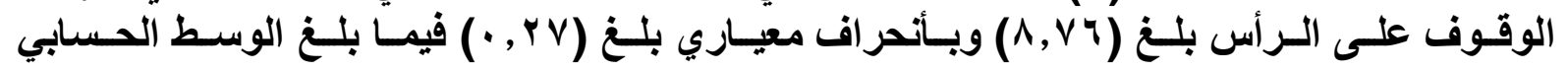

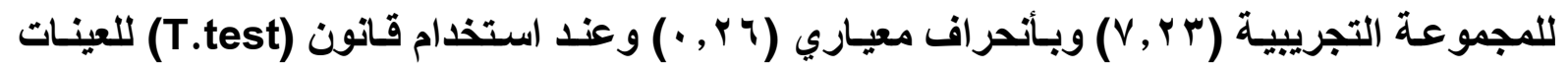

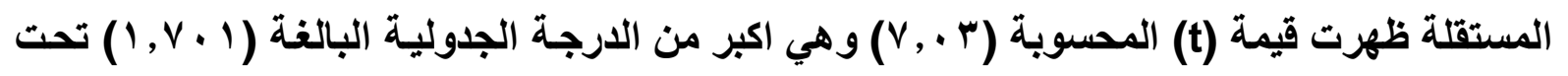

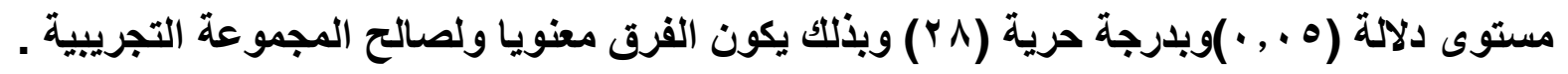

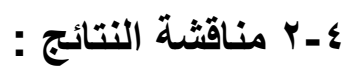


وترى الباحثة أن استخدام الموسيقى والمؤثرات الصوتية عند تعلم الحركات الأرضية المختارة

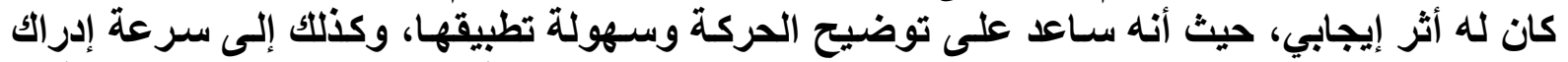

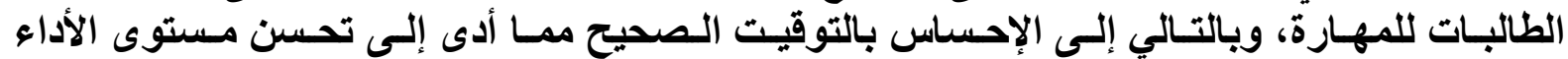

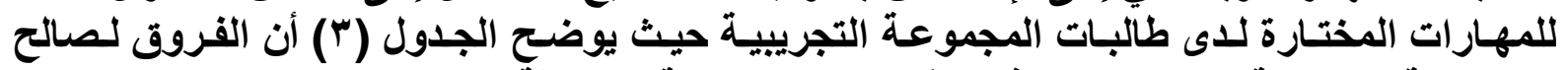

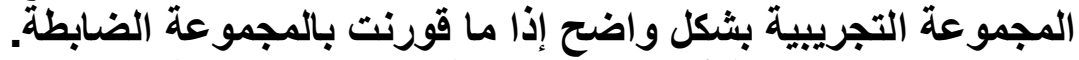

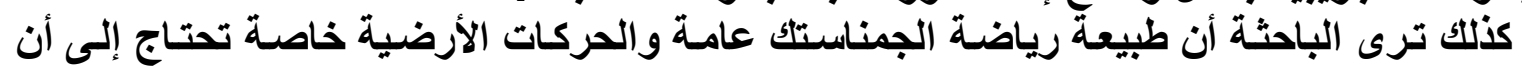

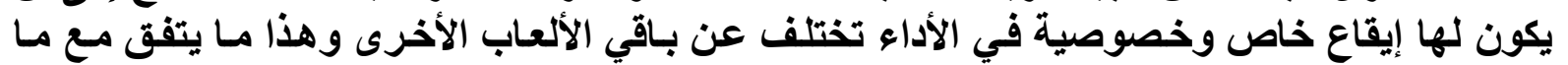

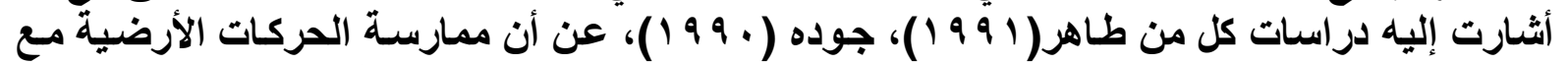

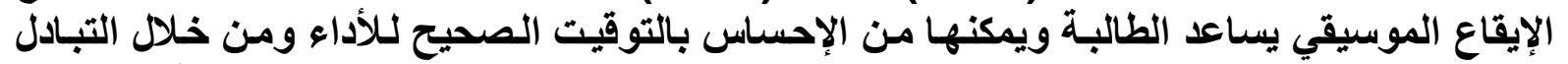
الإيقاعي للشد والارتخاء يخفف من العبء على الجهاز العصبي والعضلي مما يؤدي إلى تـأخير التعب عند الطالبات .

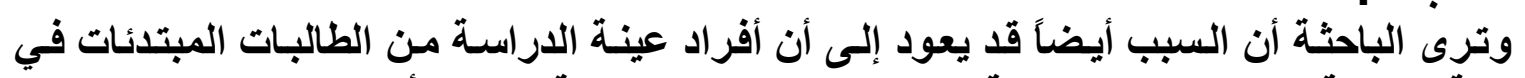

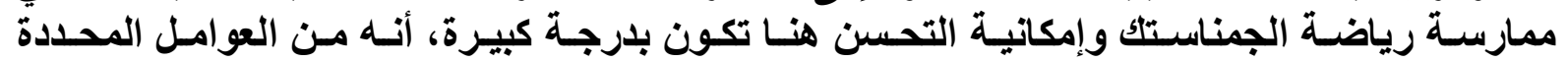

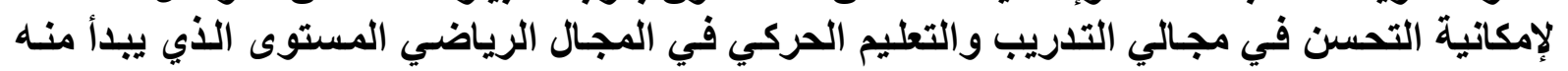
الشخص. هـ الاستتتاجات:من خلال هذه الدراسة تستنتج الباحثة:

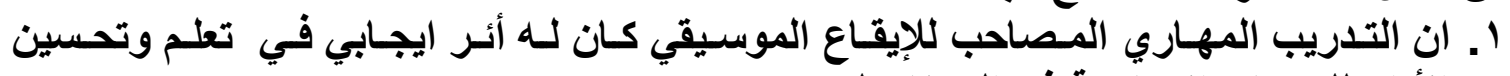

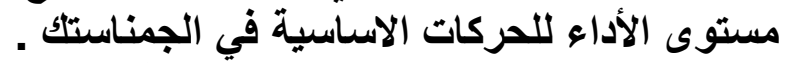

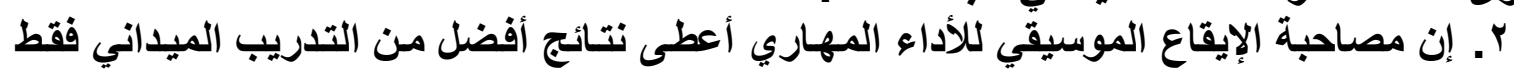
في رفع وتحسين مستوى الأداء على الحركات الأساسية لبساط الحئ الحركات الأرضية.

فـ التوصيات: في ضوء نتائج الاراسة والتي أثبتـت أن استخدام الإيقاع الموسيقي كان لـه أثر إيجابي في تعلم

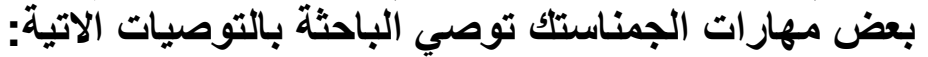

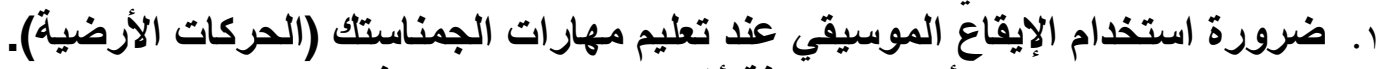

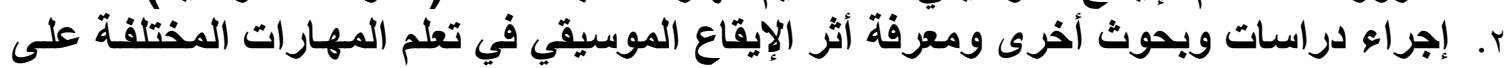
الأجهزة الأخرى وفي أنواع الرياضات ألاخرى.

\section{المصادر العربية}

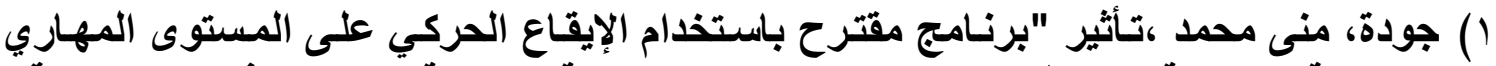

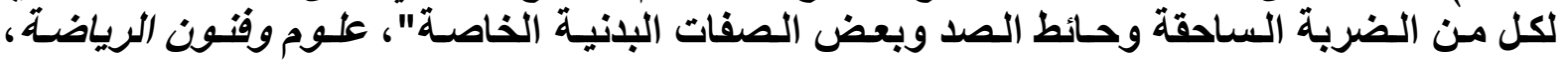

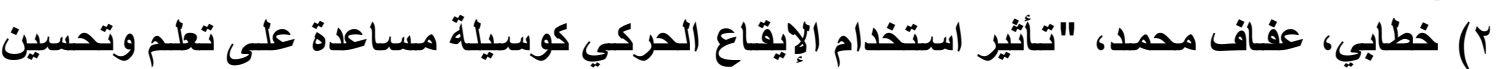

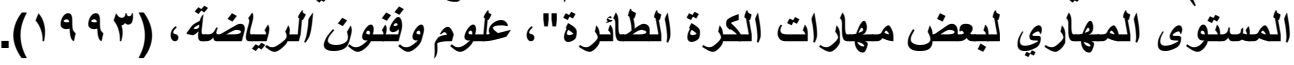




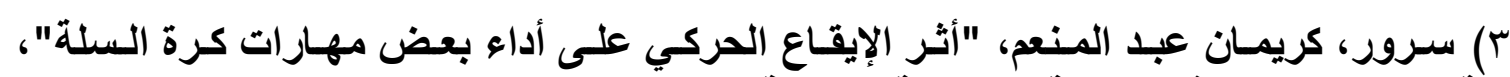

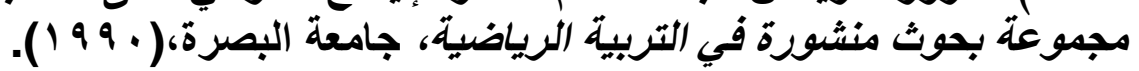

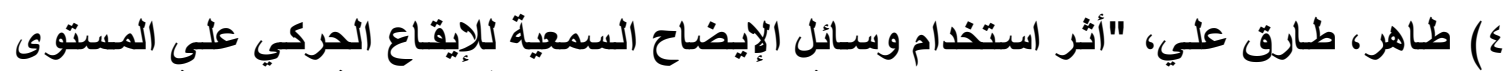

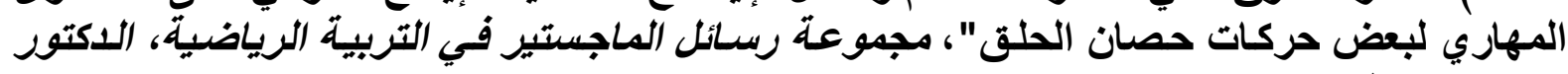

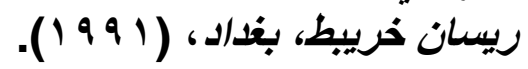
0) عباس، رابحة حسن، "التمرينات القتية الحديثة للبنات"، جامعة بغداد، ( ـ9 9 ( )).

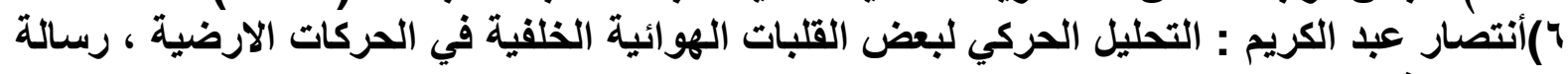

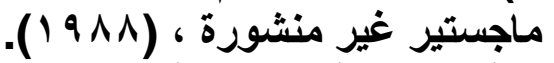

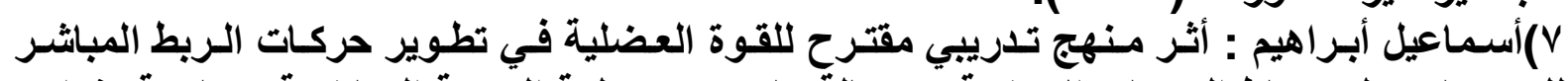

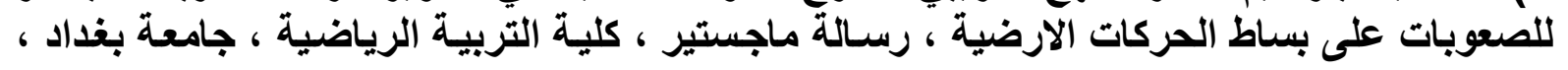
. 10.

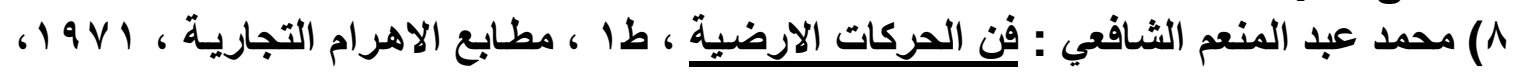
ص المصادر الأجنبية

9) Shmidt, R.A, Treffener, P.J, Shaw, B.K. \&Turvey, M.T, “Dynamical aspects of learning on interlimbi rhythmic movement pattern", Journal of Motor Behavior, 24(6), (1992) .

ملحق (1) الأسبوع الأول - - اللقاء الأول والثاني: إعداد عام على التركيز على حركات الجمناستك الأساسية. - اللقاء الثالث: إعداد خاص للجمناستك. الأسبوع الثاني - - اللقاء الرابع والخامس: تعليم مهارة الميزان الأمامي والتوازن مع الإيقاع الموسيقي.

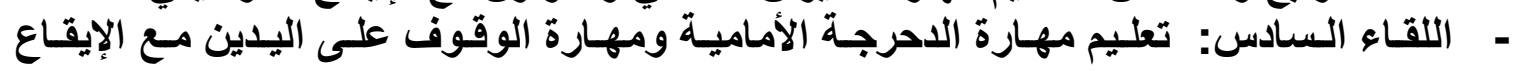
الموسيقي. الأسبوع الثالث

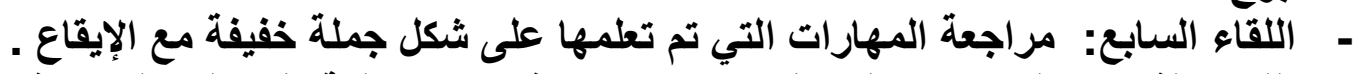

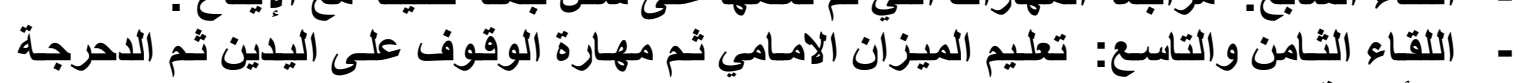
المتكورة الأمامية مع الإيقاع الموسيقي. تليمئ.

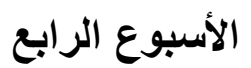
- - اللقاء العانشر والحادي عشر: مراجعة المهارات السابقة على شكل جملة متصلة مـع الإيقاع

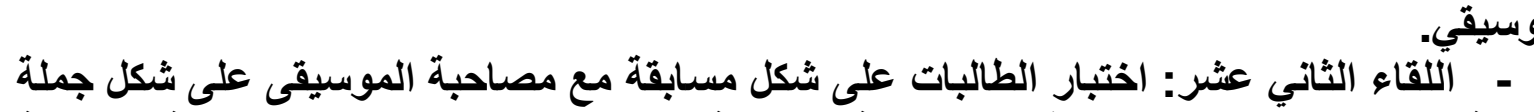

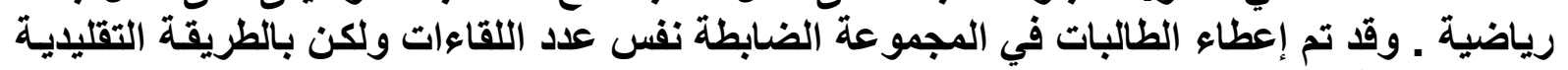
دون مصاحبة الإيقاع الموسيقي. 